\title{
Article 13. National Focal Points and Competent National Authorities
}

1. Each Party shall designate a national focal point on access and benefitsharing. The national focal point shall make information available as follows:
(a) For applicants seeking access to genetic resources, information on procedures for obtaining prior informed consent and estab- lishing mutually agreed terms, including benefit-sharing;
(b) For applicants seeking access to traditional knowledge associ- ated with genetic resources, where possible, information on pro- cedures for obtaining prior informed consent or approval and involvement, as appropriate, of indigenous and local communi- ties and establishing mutually agreed terms including benefit- sharing; and
(c) Information on competent national authorities, relevant indig- enous and local communities and relevant stakeholders.

The national focal point shall be responsible for liaison with the Secretariat.

2. Each Party shall designate one or more competent national authorities on access and benefit-sharing. Competent national authorities shall, in accordance with applicable national legislative, administrative or policy measures, be responsible for granting access or, as applicable, issuing written evidence that access requirements have been met and be responsible for advising on applicable procedures and requirements for obtaining prior informed consent and entering into mutually agreed terms.

3. A Party may designate a single entity to fulfil the functions of both focal point and competent national authority.

4. Each Party shall, nolater than the date of entry into force of this Protocol for it, notify the Secretariat of the contact information of its national focal point and its competent national authority or authorities. Where a Party designates more than one competent national authority, it shall convey to the Secretariat, with its notification thereof, relevant information on the respective responsibilities of those authorities. Where applicable, such information shall, at a minimum, specify which 
competent authority is responsible for the genetic resources sought. Each Party shall forthwith notify the Secretariat of any changes in the designation of its national focal point or in the contact information or responsibilities of its competent national authority or authorities.

5. The Secretariat shall make information received pursuant to paragraph 4 above available through the Access and Benefit-sharing Clearing-House.

\section{Overview}

Article 13 outlines the necessary institutional arrangements to be taken at the domestic level to implement the Protocol. It follows the model adopted in the Bonn Guidelines ${ }^{1}$ and in the Biosafety Protocol ${ }^{2}$ of relying on a combination of a national focal point and one or more competent national authorities. Accordingly, the former is the primary external contact point between a Party and the Secretariat of the Protocol or for users inquiring about access procedures, and the latter is responsible for granting access or issuing written evidence about PIC according to domestic requirements. The Nagoya Protocol, however, is much more detailed than the Bonn Guidelines and the Biosafety Protocol with respect to the tasks of the national focal points as key points of reference for users in understanding domestic ABS frameworks. This level of additional detail arguably seeks to address concerns expressed by both governments of developed countries and the research community, about difficulties in obtaining correct information on requirements for obtaining PIC and MAT. ${ }^{3}$

Article 13 refers to 'each Party' with a view to underlining that although the tasks for national focal points and competent national authorities are predominantly focused on access (and therefore of great importance to provider countries), the obligation applies also to Parties that see themselves as user countries. That being said, Article 13 leaves broad discretion to Parties as to the specific institutional arrangements to be put in place, which will ultimately depend on national and sub-national legal and institutional legal frameworks and practices. Accordingly, Article 13(3) explicitly provides that a Party may

1 Bonn Guidelines, paragraphs 13-14.

2 Biosafety Protocol, Article 19. For a commentary, Mackenzie et al., Explanatory Guide to the Cartagena Protocol, op. cit., 129.

3 We are grateful to Geoff Burton for drawing our attention to this point. 
designate a single entity to fulfil the functions of both focal point and competent national authority. ${ }^{4}$

Information on national focal points and competent national authorities will be included in the ABs Clearinghouse, ${ }^{5}$ possibly including information on relevant competent authorities of indigenous and local communities. ${ }^{6}$ Parties are responsible for communicating any changes to these designations to the Secretariat, so that these can be promptly reflected in the ABs Clearinghouse and that relevant stakeholders may easily find out about the key officers for the national implementation of the Protocol. ${ }^{7}$

\section{$2 \quad$ National Focal Points}

The national focal point will have a dual external function. On the one hand, it will ensure direct communication with the Secretariat of the Protocol. In that capacity, the national officer serving as focal point will receive, for example, notifications of meetings relating to the Protocol and invitations to submit views on matters on the agenda of these meetings. ${ }^{8}$ On the other hand, the national focal point is mandated to familiarize prospective users (applicants seeking access to genetic resources and traditional knowledge) with the domestic ABS framework, by providing information on procedures for obtaining PIC and establishing MAT, ${ }^{9}$ including with indigenous and local communities. ${ }^{10}$ In the latter sense, the national focal point will basically serve as a 'helpdesk' or 'information hub', whose practical role will be to enable potential users to avoid, and possibly prevent, ${ }^{11}$ unintended breaches of domestic ABs frameworks and

4 Greiber et al., Explanatory Guide, op. cit., 144.

$5 \quad$ Nagoya Protocol Article 14(2)(b). See this commentary on Article 14.

6 Nagoya Protocol Article 14(3)(a).

$7 \quad$ Nagoya Protocol Article 13(4).

8 As suggested in relation to the corresponding provision in the Biosafety Protocol by Mackenzie et al., Explanatory Guide to the Cartagena Protocol, op. cit., 129.

9 See this commentary on Article 6.

10 Nagoya Protocol Articles 6(2) and 7. See this commentary on Article 6, section 4, and Article 7.

11 If the national focal point is so empowered at the national level (since nothing in the Protocol requires this, but nothing in the Protocol prevents this domestic implementation choice either): we are grateful to Tomme Young for drawing out attention to this point. 
minimize users' costs and efforts in understanding provider countries' domestic ABS frameworks. ${ }^{12}$

The task of providing information on applicable rules and procedures or prospective users seeking access to traditional knowledge is qualified by the phrase 'where possible.' This may imply that in the case of countries with various, geographically remote or voluntarily isolated indigenous and local communities, the national focal point may not be aware of, and therefore be unable to share, relevant information. It remains to each Party, therefore, to clarify the extent of the role of national focal points with regard to these communities' requirements for access to traditional knowledge. This determination is to be made with the effective participation of the indigenous and local communities concerned, ${ }^{13}$ in light of Parties' obligation to raise awareness and support the development of community protocols and procedures ${ }^{14}$ and to take into consideration their customary laws, protocols and procedures. ${ }^{15}$ These provisions are to be interpreted and applied in a manner consistent with relevant international human rights norms and standards. ${ }^{16}$

The task of providing information on competent national authorities, as well as on relevant indigenous and local communities and stakeholders ${ }^{17}$ does not make reference to access. Consequently, Article 13(1) only provides an explicit indication of the role of national focal points in user countries, in addition to being the liaison with the Protocol Secretariat. It is left to the broad discretion of Parties to determine the role of national focal points when a State acts as the user country in a specific ABS transaction.

Competent national authorities must be authorized by a Party to act on its behalf 18 in relation to two implementation functions: first, granting access or issuing written evidence that access requirements have been met; and second,

12 Greiber et al., Explanatory Guide, op. cit., 144; see also discussion of information to be provided: ibid., 145-146.

13 UNDRIP Articles 19 and 32(2); ILo Convention No. 169, Article 6(2).

14 Nagoya Protocol Articles 21(i) and 12(3)(a). See this commentary on Article 21.

15 Nagoya Protocol Article 12(1). See this commentary on Article 12, section 2.

16 See Introduction to this commentary, section 4.

17 Nagoya Protocol Article 13(1)(c).

18 As suggested in relation to the corresponding provision in the Biosafety Protocol by Mackenzie et al., Explanatory Guide to the Cartagena Protocol, op. cit., 129-130. 
advising on procedures and requirements for PIC and MAT. As a consequence, although Article 13(2) clearly indicates that 'each Party' should designate competent national authorities, it remains unclear what tasks will be performed by relevant officers in user countries. ${ }^{19}$

As to the advisory role of competent national authorities, this is a complementary function to that of the national focal point. In that regard, the Protocol provides significantly less details than the Bonn Guidelines. The latter specify that competent national authorities should be responsible for advising on: the negotiating process and the requirements for obtaining PIC and establishing MAT; monitoring and evaluation of ABS agreements; implementation/enforcement of ABS agreements; processing of applications and approval of agreements; conservation and sustainable use of the genetic resources accessed; mechanisms for the effective participation of different stakeholders, as appropriate for the different steps in the process of $\mathrm{ABS}$, in particular indigenous and local communities; and mechanisms for the effective participation of communities, while promoting the objective of having decisions and processes available in a language understandable to relevant communities. ${ }^{20} \mathrm{~A}$ Party may opt for introducing such guidance in its national legislation in that regard. ${ }^{21}$

As to its role regarding access, the Protocol envisages that the national competent authority will be necessarily tasked with issuing written evidence that access requirements have been met. ${ }^{22}$ The Protocol also indicates that the same authority may be mandated under the domestic ABs framework to grant access (i.e., provide PIC and engage in MAT negotiations). Notably, the provision is silent on whether national competent authorities are responsible for submitting permits to the ABs Clearinghouse, ${ }^{23}$ thereby elevating them to an internationally recognized certificate of compliance. ${ }^{24}$ It can be argued that to enhance legal certainty and predictability at the international level, domestic ABs legislation could specify that competent national authorities are the only authorized to submitting permits to the ABs Clearinghouse. In addition, through a combined reading of several Protocol provisions, it could be argued that national competent authorities in user countries will be responsible for

\footnotetext{
19 We are grateful to Tomme Young for a useful exchange of ideas on this provision.

20 Bonn Guidelines, paragraph 14(1). We are grateful to Geoff Burton for drawing our attention to this point.

21 See Introduction to this commentary, section 2.

22 Nagoya Protocol Article 13(2). This complements the obligation under Article 6(3)(d).

23 Nagoya Protocol Article 14(2)(c). This is also the case of Nagoya Protocol Article 6(3)(e): we are grateful to Evanson Chege Kamau for drawing our attention to this point.

24 Nagoya Protocol Article 17(2). See this commentary on Article 17, section 3.
} 
managing the information received by checkpoints ${ }^{25}$ and posting this and other required information to the ABs Clearinghouse, as appropriate. ${ }^{26}$ In combination with the requirement that Parties notify the Secretariat of the contact information of their national focal point and competent authorities, ${ }^{27}$ this would further enhance legal certainty and assist in maintaining the integrity and accuracy of the information in the ABs Clearinghouse. ${ }^{28}$

As revealed by the expression 'as applicable', however, the Protocol does not prevent Parties (or their national competent authority in that regard) ${ }^{29}$ from delegating the power to grant access to other individuals or entities. ${ }^{30}$ That may be the case of Parties deciding to use a decentralized system of granting access due to the federal or devolved nature of government, ${ }^{31}$ or Parties preferring to delegate such power to non-State entities, such as genebanks or research centers. In addition, in the case of genetic resources held by indigenous and local communities ${ }^{32}$ and/or traditional knowledge, the authority to grant PIC or approval and involvement will be found within the relevant communities. This determination is to be made with the effective participation of the indigenous and local communities concerned, ${ }^{33}$ taking into consideration these communities' customary laws, protocols and procedures. ${ }^{34}$ Once again, Parties' obligation under the Protocol to support the development

25 See Nagoya Protocol Article 17(1)(a)(iii), which requires information from checkpoints to be provided to 'relevant national authorities.' See also this commentary on Article 17, section 2.

26 Nagoya Protocol Article 14(2).

27 Nagoya Protocol Article 13(4).

28 This would result in avoiding the posting of drafts by organizations or individuals - a problem experienced with the Biosafety Clearinghouse. See Tomme Young, "Use of the Biosafety Clearing-house in Practise," in Legal Aspects of Implementing the Cartagena Protocol on Biosafety, ed. Marie-Claire Cordonier Segger, Frederic Perron-Welch and Christine Frison (Cambridge: Cambridge University Press, 2013), 137.

29 As also foreseen in the Bonn Guidelines, paragraph 14(2).

$30 \quad$ Young, "An International Cooperation Perspective," op. cit., 459 fn. 22.

31 For a more general discussion of questions of multi-level governance of ABs arising from the implementation of the Protocol in context of federal or highly decentralised States, see Singh Nijar, "An Asian Developing Country's View," op. cit., 264-266; and Lago Candeira and Silvestri, "Challenges in the Implementation of the Nagoya Protocol," op. cit., 277 and 287-292.

$32 \quad$ Nagoya Protocol Article 6(2).

33 See fn. 13 above.

34 Nagoya Protocol Article 12(1). 
of community protocols and procedures ${ }^{35}$ is relevant to this end, as are international human rights norms and standards. ${ }^{36}$ As noted above, for reasons of legal certainty and predictability at the international level, the designated competent authorities notified to the Secretariat would be the ones issuing written evidence that access requirements have been met.

The Protocol explicitly allows Parties to designate more than one competent national authority, and to specify the nature of their ABs-related (decisional or administrative) authority in detail, so each of these authorities could be responsible to grant access on genetic resources of different nature or for different intended uses. ${ }^{37}$ The Protocol thus specifically requires Parties choosing to designate more than one competent national authority, to inform the Secretariat about which authority is responsible for dealing with which type of genetic resources. ${ }^{38}$ As a result, specific institutional arrangements for granting access may vary significantly from one Party to another, and Parties will be well advised to set out in detail in their domestic ABs frameworks the specific arrangements for granting PIC. ${ }^{39}$ In that respect, a distinction will likely be drawn between access in situ and ex situ. As regards the former, the decisionmaking process for reaching a decision on access is likely to involve a wide range of national authorities, including those involved in the implementation of other relevant international obligations, such as under the Convention on International Trade in Endangered Species and on animal and plant health, ${ }^{40}$ or under the law of the sea, ${ }^{41}$ as well as stakeholders. Parties thus will be well advised to spell out in their national ABs frameworks the specific domestic procedures for consultations to be carried out prior to granting access, ${ }^{42}$ or to devise a 'one-stop-shop' system to streamline procedures. ${ }^{43}$ The latter may

\footnotetext{
35 Nagoya Protocol Article 12(3)(a).

36 See Introduction to this commentary, section 4.

37 Greiber et al., Explanatory Guide, op. cit., 146.

38 Nagoya Protocol Article 13(4).

39 Particularly in view of the Protocol requirement for a clear and transparent written decision on access, in a cost-effective manner and within a reasonable period of time: Nagoya Protocol Article 6(3)(d).

40 We are grateful to Tomme Young for drawing our attention to this point.

41 Salpin, "Law of the Sea," op. cit., 168.

42 As suggested in relation to the corresponding provision in the Biosafety Protocol by Mackenzie et al., Explanatory Guide to the Cartagena Protocol, op. cit., 130.

43 E.g., Institute for European Environmental Policy, "Study to analyse legal and economic aspects of implementing the Nagoya Protocol on ABS in the European Union," (undated) accessed 1 November 2013, <http://ec.europa.eu/environment/biodiversity/
} 
also be useful in situations where access to one or more samples is sought from a collection in a provider country. ${ }^{44}$

international/abs/pdf/ABS\%20FINAL\%20REPORT\%20-\%20Annexes.pdf>, 28; Martin Brink, "Implementation of Access and Benefit Sharing Policies in Sub-Sahara Africa: Inventory, Analysis and Proposals" (June 2013), accessed 11 November 2013, <http:// edepot.wur.nl/280508>, 13 and 19. See also discussion in Evanson C. Kamau and Gerd Winter, "Streamlining Access Procedures and Standards," in Kamau and Winter, Genetic Resources, Traditional Knowledge and the Law, op. cit., 38.

44 At least in the case of the EU, it appears that it is mostly university-based researchers and scientists affiliated with ex situ collections that engage in bioprospecting activities, usually with an explicitly non-commercial purpose. Commercial users of genetic resources, in contrast, rarely collect genetic resources in the wild but source new material from collections, except in some particular niches of innovation, such as the biocontrol industry, parts of industrial biotechnology, and some small pharmaceutical biotechnology companies. See European Commission, Impact Assessment (Part 1), $\operatorname{SwD}(2012) 292$ final, 15. 